Vol. 5, Issue 1, February 2020, pp. 13-25

DOI: $10.23917 /$ jramathedu.v5i1.9675

p-ISSN: 2503-3697, e-ISSN: 2541-2590

\title{
Promoting creative thinking for gifted students in undergraduate mathematics
}

\author{
Parinya Sa Ngiamsunthorn \\ Department of Mathematics, Faculty of Science, King Mongkut's University of Technology Thonburi, Thailand \\ ${ }^{*}$ Corresponding author: parinya.san@kmutt.ac.th
}

\begin{tabular}{l} 
ARTICLE INFO \\
\hline Article history: \\
Received: 26 December 2019 \\
Revised: 28 January 2020 \\
Accepted: 30 January 2020 \\
Published online: 28 February \\
2020 \\
Published regularly: February \\
2020
\end{tabular}

Keywords:

Gifted students, creative thinking, mathematics, techniques and methods
ABSTRACT

Gifted students need a form of special education through extracurricular and learning experiences because they have extraordinary potential in terms of intelligence, creativity, social and mentality, compared to other students. This study aims to investigate various teaching and learning approaches designed for gifted students, and to constitute appropriate techniques that enhance their creative thinking in mathematics. The participants of this study were first-year gifted students enrolled in fundamental mathematics courses towards their undergraduate engineering programs at a science and technology-based university in Thailand. This study discovered that an adequate use of challenge-based learning, problem solving process, project-based learning, well-designed questions and in-depth learning style in the classroom effectively fostered their insightful and creative thought. Moreover, an online tool such as Facebook could be used as a learning platform outside the classroom to engage them in online discussion and collaboration and to challenge their thinking. Ultimately, based on students' feedbacks and evaluation, this study found that a combination of these techniques and methods built up a more comfortable and motivating atmosphere that helped them for creative thinking and corresponded to their needs and satisfaction.

(C) 2020 Universitas Muhammadiyah Surakarta

\section{Introduction}

It is undeniable that mathematics plays an important role in countries' development in this technological change. Especially in countries with both well-established and developing scientific and industrial traditions, it is necessary to have a sufficient number of people with high-level mathematical capabilities (Taber, 2010). Accordingly, people need to learn mathematics offered in universities and colleges to support this technologicallyoriented society. Nonetheless, each course offering in mathematics needs to be designed appropriately for students' differentiated abilities, for example, a group of gifted students who need special teaching techniques and methods to ensure that they will acquire effective learning and adequate support. To this extent, the giftedness of students determines a suitable form of teaching techniques and methods.

Gifted students can be defined as group of students who possess extraordinary potential in one or more domains of human abilities including intelligence, creativity, social and mentality relative to the top ten percent of members of the same age group (Gagné, 
1985). Alternatively, gifted students are those students who can score in the top 1.5 percentile for their ages based on a unique, higher-quality cognitive and emotional perspectives as well as intelligence and creativity (Khalil \& Accariya, 2016). In other words, they tend to be cognitively and affectively more advanced (Plunkett \& Kronborg, 2011). Moreover, some may regard them as those who have achieved a high level of excellence in academic intelligence examination (Nevo \& Rachmel, 2009) and those who are dissimilar with other students in terms of their cognitive, affective and social needs (Shaywitz et al., 2001). Accordingly, the definition of gifted students should not be understood only for their academic performance but also their mental and social values (Vidergor \& Reiter, 2008) such as self-esteem, motivation, and social influences because these can either support or extinguish their giftedness (Gagné \& Gagnier, 2004). For example, the learning environment that does not acknowledge their needs will undermine their creative achievement (Burney, 2008) whereas, in the atmosphere that supports their enjoyment, motivation, and acceptance, they will be encouraged to learn and think more. As a result, their mental and social conditions are equivalently important factors to be considered for developing techniques and methods that support their creative thinking in mathematics (Fraser-Seeto, Howard, \& Woodcock, 2013). In order words, the appropriate techniques and methods should correspond to the gifted students for their mental and social needs.

Basically, there are three approaches that guide gifted education (Leikin, 2011), however, they are not inclusive as some techniques and methods could also be designed for teaching gifted students as explained earlier in this study. Firstly, acceleration is advanced learning in excess of the contents that are academically prescribed at their normal level. This acceleration usually takes the form of extracurricular because they have faster rates of growth in academics and different needs compared to their same-age peers. Secondly, the broadening is a pattern of learning more topics and materials than was required by curriculum to affirm that they would acquire the breadth of knowledge. Lastly, deepening is learning in-depth to guarantee that students would develop their expertise on the topics, for example, the learning that underlines mathematical theories or the learning that necessitates for an appreciation into the nature of mathematics. Moreover, such in-depth knowledge is also a basis for insightful and creative thinking. The key components for indepth learning approach demand that the teachers should: 1) focus on the conceptual content, 2) emphasize inquiry and production, 3) encourage on higher-level thinking, and 4) support intra- and inter-personal learning and offering of pace, variety, and choice (Taber, 2010). Nonetheless, in practice, the teachers normally apply a combination of these three approaches whereas one particular approach may be given greater weight than others depending on their effectiveness in enhancing students' creative thinking.

Challenge-based learning is another engaging technique that could be used to strengthen creative thinking of gifted students while solving challenge problems because an appropriate level of this challenge would enable them to demonstrate their tenacity and high levels of thinking rather than delivery of over-generalized explanations and inadequate information which causes them bored and require a great amount of time and effort without demand of thoughtful analysis (Taber, 2010). Accordingly, the teachers may adopt some tasks with sufficient challenge that has a motivational effect on their abilities to innovate and think (Diezmann \& Watters, 2002).

Several misperceptions exist in relation to gifted students and thus become barriers to their learning. For instance, they might be erroneously regarded as those who are already academically advantaged and do not require any specially designed techniques and methods, compared to other students who have more difficulties (Lassig, 2009) whereas, in fact, they are unlikely to succeed themselves without adequate support (Plunkett, 2002). 
Moreover, their excellence, productivity, and desire for a challenge may not be fully comprehended and ignored by the teachers who lack the requisite knowledge, leading to underachieved gifted education (Ziv \& Sorongon, 2011). In addition, the teachers may show their unconscious negative attitudes towards gifted students and do not have an awareness of the complexity of the issue revolving around them (Geake \& Gross, 2008). Therefore, teachers' understanding of gifted students is a primary step for developing appropriate techniques and methods.

The teachers perform the most crucial role in gifted education as Colangelo and Davis, (2002) strongly emphasized on this issue because good teachers can have a lasting positive effect on their creative thought in mathematics as well as on their development and achievement (McCoach \& Siegle, 2007). Moreover, they are highly influenced by their teachers and then place great expectations on teachers' qualities and willingness to enable them to make use of their capabilities more effectively and to progress continuously to the achievement. For example, they expect that their teachers have a high degree of knowledge on the area of expertise, and have abilities to deliver a challenge in learning through use of techniques and methods designed to promote their creative thinking as a result of having an understanding of their cognitive and social values, mentality and development (Julie Landvogt, 2001). Moreover, teachers must also have the academic skills in subjects, which allow maximum efficacy in teaching and learning (Milgram, 1979). In addition, it was recommended that teachers should have the following: 1) the proper identification of what they know or do not know, 2) the explanation in a way that motivates and challenges them, 3) providing the constructive feedback and giving them the opportunity to adapt themselves to the teaching techniques and methods, and 4) cultivating motivation and selfesteem in them (Khalil \& Accariya, 2016). As a result, teaching in gifted education is neither straightforward nor easy (Troxclair, 2013). The teachers' role is unavoidably important for gifted education.

While creativity is one of the potential possessed by gifted students, this potential in creative thinking is also essential skills to be applied across their mathematics education and their mathematics-related profession that will benefit countries' innovative development. Importantly the mathematical invention is based on both reasoning and imagination. So teachers should build up more productive techniques and methods to promote their creative thinking (Diezmann \& Watters, 2000).

For this purpose, creative thinking represents a different style of thinking altogether in the finding of different solutions and interpretations, making various mathematical connections, applying different techniques, and thinking originally and differently. In other words, creative thinking is a part of the problem solving process which requires the achievement of the new approaches or results (Leikin, 2011).

In this study, a discussion begins with teachers' preparation and techniques before the classroom. Secondly, this study examines an overview of various approaches used in gifted education and suggests appropriate techniques and methods promote creative thinking of mathematically gifted students. Based on students' reflections and evaluations, this study analyzes the outcome from the use of these techniques and methods.

\section{Research Questions}

This research is a qualitative study to identify effective teaching methods for gifted students. The study aimed to investigate various approaches used to teach gifted students and to construct appropriate techniques and methods that enhance the creative thinking of gifted students in mathematics. To this end, three research questions were addressed: First, how should techniques and methods be created to promote the creative thinking of 
gifted students in mathematics? Second, to what extent various approaches can be employed appropriately in gifted education? and Third, what response would gifted students give relative to the techniques and methods used to promote their creative thinking?

\section{Research Methods}

\section{Participants}

The participants of this study were 23 first-year gifted students (18 males and 5 females age 18 to 19 years) enrolled in two mathematics courses: MTH101 Mathematics I and MTH102 Mathematics II in undergraduate engineering programs at the Department of Mathematics, Faculty of Science, King Mongkut's University of Technology Thonburi, Thailand between 2015 and 2016. These courses involve differentiation and integration for functions of one and several variables. The aim of the courses is to develop fundamental mathematics which is essential to the practice of engineering professionals. It is expected that engineering graduates are able to apply knowledge of mathematics, science, and engineering to solve challenging problems and are able to analyze and interpret solutions. As gifted students, this group of students was selected on the basis of their academic results and their intelligence quotient or cognitive ability assessments by the University's Gifted Education Office King Mongkut's University of Technology Thonburi to be registered in the gifted education program. Moreover, since the language of instruction for these mathematics courses was officially English, the participants had English proficiency in reading, speaking, writing and listening. The study also involves a male teacher who participated in preparing course materials, lecturing and classroom observation. The teacher background is a pure mathematician who was awarded excellence in teaching by the university in the early career profession.

\section{Data Collection Instrument}

This study was primarily the documentary-based research which involved the extensive use of relevant journal articles, research papers and other academic documents from accepted sources. Data collection in this study includes:

1. Student examination scripts and project works for evaluation of their creativity

The works of all 23 students were collected from the midterm and final examination papers, and project presentation and report. The indicators of creative thinking ability focused in this research are flexibility (generate various approaches of solving problems), originality (use a new and original technique to solve problems) and elaboration (explain logically based on mathematical procedures to solve problems).

2. Facebook group questions and comments

The comments and questions posted in the Facebook group for the class were collected.

3. Students feedback from an online questionnaire

The questionnaire is divided into two parts. The first part consists of three statements regarding students' attitudes towards teaching and learning which are lecture, questions and exercises, and project-based learning on a Likert 5 point scale on level of satisfaction. The second part consists of four open response questions on students' attitudes in the class. The questions are: what is your feeling about course content? what are the skills you have developed from the class and to what extent? what is the difference in this class compared to your previous mathematics classes? What are the main difficulties you experienced from the class? 
4. Observation of classroom by a teacher on the students' participation and engagement in class activities such as discussion and tutorial sessions.

Data analysis was done by using the triangulation method by comparing data from the examination, online questionnaire, teacher observation, and comments on Facebook.

\section{Results and Discussion}

How should techniques and methods be created to promote the creative thinking of gifted students in mathematics?

As previously noted, teachers have an influential role in the development, learning and creative achievement of gifted students .Firstly, this study discovered that teachers required both quantitative and qualitative expansion of their knowledge to deliver the lessons that maximize understanding and thinking abilities of gifted students. Teachers also needed to conduct accurate research into academic topics and related issues to educate the gifted students deeply and provide prompt answers to their questions .In this way, this produced a motivating and challenging learning environment that helped gifted students to absorb the information and stimulate them in creative thinking effectively. Thus teachers' role would have a great impact on gifted students' development in creative thinking. This was reflected from students' responses via an online questionnaire that they experienced different classroom environment which encourages each other through stimulating questions compared to other classes. In addition, students felt that they were given enough time to think about course materials rather than to just memorize the method.

Secondly, this study revealed that teachers were also obliged to encourage their active learning with a variety of building materials and demonstrations that promoted their cooperation and discussion in the classroom rather than focusing too much on theories and textbooks. While this technique prevented them from boredom and self-isolation, it also effectively persuaded them to increase their participation in the classroom for active learning. In particular, there were students'comments from an online questionnaire that they have the opportunity to do exercises in front of the class to obtain instant feedback and develop reasoning through an explanation to the class. Furthermore, this study found that it was compulsory to create a challenge within the classroom through the problem solving process and project-based learning that gave them opportunities to showcase their knowledge and abilities whereas the lecture-based learning would deter them from curiosity and lock their hidden potential .Based on the problem solving process and project-based learning, they would be given the opportunity to investigate and explore real-world problems by themselves and with their peers .As they get involved in designed cooperation, this technique would lead to meaningful relationships and mutual assistance among them .As a result, this study found that the use of this technique benefited satisfactorily with their needs and enhanced their performance as they provided their positive comments that "I can build up the relationship with friends and the teaching encouraged me to learn more", "I can use the knowledge acquired from the class to teach my friends", or "I can adapt the knowledge acquired from the class to use for other subjects".

The findings from this study would suggest some techniques and methods that help the teachers in their preparation . 
To what extent various approaches can be employed appropriately in gifted education?

This study found that teachers could enhance the creative thinking of gifted students through a well-designed question that required them to figure out the solution by applying all knowledge, approaching the problem from different directions and decision-making. In solving this question, they were provided certain freedom to deal with problem whereas they had to make selection and application of their relevant knowledge on the basis of their choices and analysis. This technique encouraged their thoughtful and in-depth consideration for any possible approaches to tackle the problem beyond the proof and examples given in the classroom. Moreover, teachers were also able to estimate their students' actual understanding, thinking progress and creative achievement, and unexpectedly gifted students might develop new results. From the online questionnaire, students reflected that they have developed analytical thinking skills extensively to combine various knowledge for solving complex question. They also learned to be more careful when tackling the question and gained a new idea for solving problems.

Furthermore, this study's finding revealed that teachers could introduce projectbased learning to engage their students in creative thinking. This study designed the project called "Water Wheel project" in which gifted students were given a precise question to find the volume flow rate of the water wheel, which involves finding the volume by double or triple integral (Figure 1).

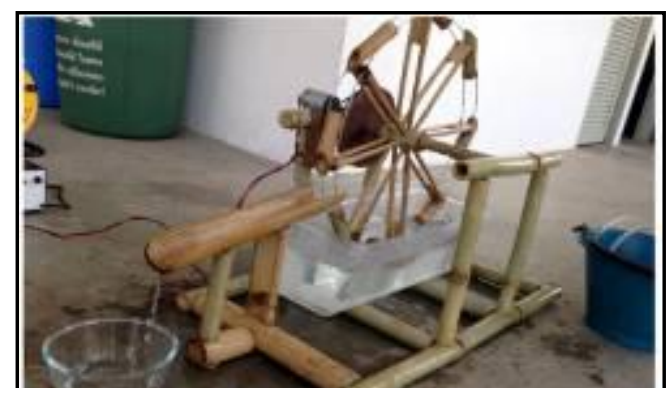

Find the volume flow rate of the water wheel

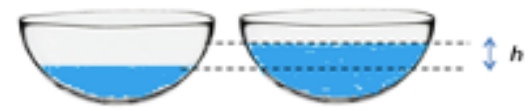

Figure 1. Water wheel project

There were many possible approaches to solve this question. In this project-based learning, the teachers provided some hints at the beginning stage about the data need to be obtained. Later, students began to establish their own methods for completing the project. From the project presentation, it can be seen that students developed creative thinking when they need to formulate a mathematical representation of the real-world situation.The project encourages students to think creatively compare to a usual exercise on integration where the function is given. Figure 2 shows various approaches to find a function that describes the surface of a bowl created by students. 

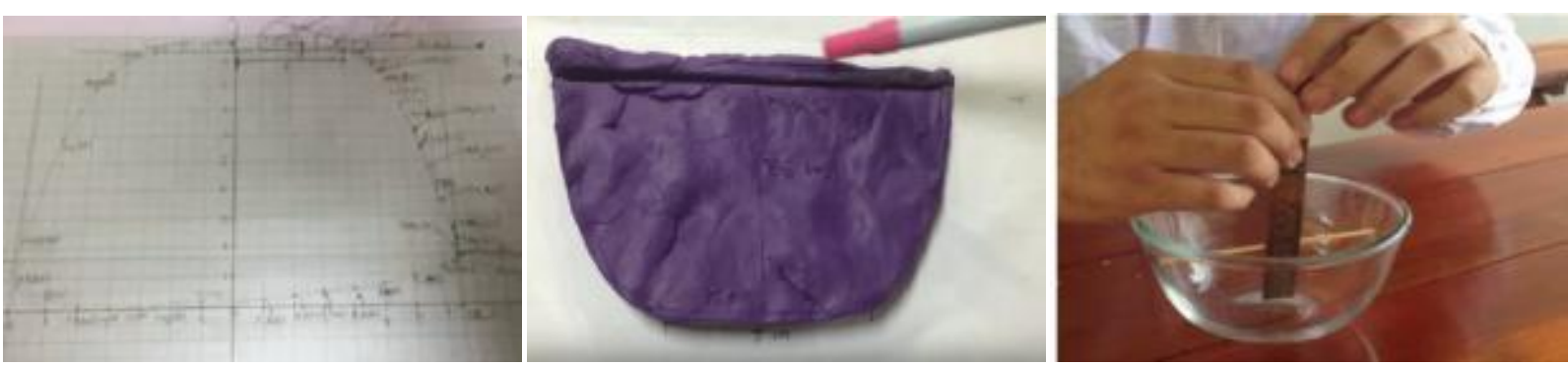

Figure 2. Various approaches for finding a function that describes the surface of a bowl created by students.

This form of learning constituted a significant intellectual challenge that required them to use their mental simulation to run the project and to apply what they learned to real-life experiences. While working on this project, they constructed the structural planning based on their review, knowledge and realistic time scales through the process of evaluation and development. Thus they had the passion to think and for their interactions, leading to a positive atmosphere of constant engagement and learning. This finding is consistent with Philip (1998) previous studies that explained that their collaboration could contribute to effective learning. Moreover, this technique helped to transfer those who struggle with the theories into a suitable context for devising challenges (Taber, 2008). Therefore, the project-based learning that enabled gifted students to cope with a real-life complexity would benefit them for analytical and creative thought.

Moreover, online tools can also be used to assists gifted students to foster their mathematical creativity (Leikin, 2011) because it builds an online active learning environment which is one of the most effective ways of their learning (Clarke \& Bana, 2001). This study found that Facebook was a social networking site where questions and answers could be posted to inspire the discussion and collaboration among gifted students, and thus to challenge their creative thinking. Additionally, this study also discovered that Facebook was a major medium for interaction between teachers and gifted students outside the classroom, so teachers could afford adequate support for their improvement and advancement. From the online questionnaire, students had positive response to the use of Facebook as some of them viewed that "he can use Facebook to ask questions that he has from his own study and this helped him to develop ideas for further learning incredibly "or "he can post the answer to question and teacher can correct it". Therefore, Facebook is another platform that could be used to enhance gifted students' creative thinking and successfully gained acceptance from them.

This study implemented challenge-based learning into questions by formulating questions that were intended to challenge their knowledge and creative thinking rather than assessing what they learned. In this way, teachers could evaluate gifted students from their competences to cope with challenges posted and their intellectual process of conceptualizing, analyzing, solving and reaching the outcomes. Moreover, teachers should also give extra marks or special marks in order to motivate them to attempt and work on these questions because this study found that getting gifted students motivated is particularly important for their gifted level of performance, and those students, who are highly motivated, would be more interested and focused on the tasks. One example used in this study related to the topic of evaluation of limit (Figure 3). For this question, students could produce different correct answers.

The students' working to solve this problem is given in Figure $4-5$. Most students could answer this question by applying L'Hopital rule twice as shown in Figure 4. However, 
some students also produced an alternative approach of using trigonometric identities and some limit properties to solve the problem as in Figure 5.

Evaluate the limit

$$
\lim _{x \rightarrow 0^{+}}\left(\frac{1}{x}\right)^{\sin x+x}
$$

Solution: The limit is of the form $\infty^{0}$. Let $y=\left(\frac{1}{x}\right)^{\sin x+x}$. Then

$$
\ln y=(\sin x+x) \ln \left(\frac{1}{x}\right)=-(\sin x+x) \ln (x) .
$$

Hence, we get by using L'Hopital rule that

$$
\begin{aligned}
\lim _{x \rightarrow 0^{+}} \ln y & =\lim _{x \rightarrow 0^{+}}-(\sin x+x) \ln (x) \\
& =\lim _{x \rightarrow 0^{+}}-\frac{\ln (x)}{\frac{1}{(\sin x+x)}} \quad \frac{\infty}{\infty} \text { form } \\
& =\lim _{x \rightarrow 0^{+}}-\frac{\frac{1}{x}}{-(\sin x+x)^{-2}(\cos x+1)} \\
& =\lim _{x \rightarrow 0^{+}}\left(\frac{\sin x+x}{x}\right)\left(\frac{\sin x+x}{\cos x+1}\right) \\
& =\lim _{x \rightarrow 0^{+}}\left(\frac{\sin x}{x}+1\right)\left(\frac{\sin x+x}{\cos x+1}\right) \\
& =\left(\lim _{x \rightarrow 0^{+}} \frac{\sin x}{x}+1\right)\left(\frac{\lim x \rightarrow 0^{+}(\sin x+x)}{\lim _{x \rightarrow 0^{+}}(\cos x+1)}\right) \\
& =(1+1)\left(\frac{0+0}{1+1}\right) \\
& =0 .
\end{aligned}
$$

Therefore,

$$
\lim _{x \rightarrow 0^{+}}\left(\frac{1}{x}\right)^{\sin x+x}=\lim _{x \rightarrow 0^{+}} y=e^{\left(\lim _{x \rightarrow 0^{+}} \operatorname{Ln} y\right)}=e^{0}=1 .
$$

Figure 3. Example of solution for a question on the evaluation of a limit

$$
\begin{aligned}
& \begin{array}{l}
\text { 6. Evaluate the limit } \\
\text { Soln } 1^{n} \text { Let } y=\left(\frac{1}{x}\right)^{\sin x+x} \lim _{x \rightarrow 0^{+}}\left(\frac{1}{x}\right)^{\sin (x)+x} \cdot\left[\infty^{0} \text { form }\right]
\end{array} \\
& \text { take } \ln t=\ln y=(\sin x+x) \ln \left(\frac{1}{x}\right) \\
& \text { take } \lim _{x \rightarrow 0^{+}} ; \ln y=\lim _{x \rightarrow 0^{+}}\left[(\sin x+x) \ln \left(\frac{1}{x}\right)\right] \quad[0 . \infty \text { form }] \\
& =\lim _{x \rightarrow 0^{+}} \frac{\ln \left(\frac{1}{2}\right)}{\frac{1}{\sin x+x}} \quad\left[\frac{\infty}{\infty} \text { form }\right] \\
& =\lim _{x \rightarrow a^{+}} \frac{\frac{\sin x+x}{\left(-1-x^{-2}\right)^{\prime}}}{-(\sin x+x)^{-2}(\cos x+1)} \quad \text { [Using. L'Hopital] } \\
& =\lim _{x \rightarrow 0^{+}} \frac{\left(-\frac{1}{x}\right)}{f \frac{\cos x+1}{(\sin x+x)^{2}}} \\
& =\lim _{x \rightarrow 0^{+}} \frac{(\sin x+x)^{2}}{x(\cos x+1)} \quad[\because \text { form }] \\
& =\lim _{x \rightarrow 0^{+}} \frac{2(\sin x+x)(\cos x+1)}{x(-\sin x)+(\cos x+1)} \quad \text { UUsing L'Hopitd) } \\
& \ln y=\frac{0}{2}=0 \\
& \text { take ; } \begin{aligned}
e^{\ln y} & =e^{0} \\
y & =1
\end{aligned} \\
& \text { i. } \lim _{x \rightarrow 0^{+}}\left(\frac{1}{x}\right)^{\sin x+x}=1
\end{aligned}
$$

Figure 4. Student's solution using L'Hopital twice 


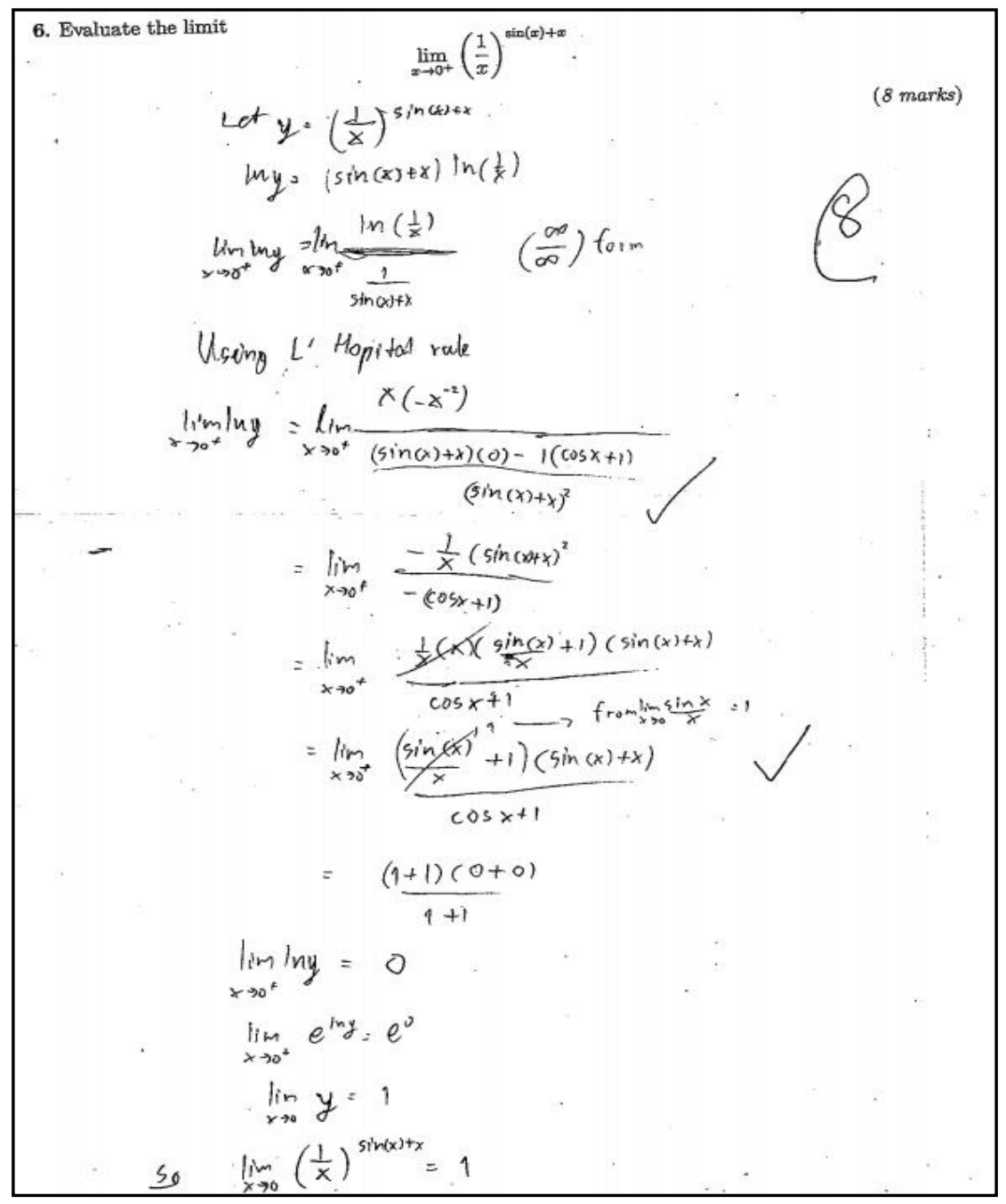

Figure 4. Student's solution using trigonometric identities

This study found that gifted students came to the classroom with a broad range of pre-existing knowledge and prior experiences as a result of their self-regulatory learning, thus they preferred the learning format that significantly intensified their understanding and provided in-depth explanations for their questions that incurred during their own studies. This was reflected from questions and comments on the Facebook group for a broad range of questions that reflect prior knowledge about the subjects. Moreover, their deeper knowledge also offered a deeper insight into their thinking process. On the other hand, advanced learning and broad knowledge are what they could gain more easily from textbooks and researches. This study's finding is in the same line with the previous research of Koshy (2001) which stated that when they were motivated with in-depth knowledge, they would explore and learn more. Similarly, the previous study of Taber (2010) also supported the finding of this study because it stated that the teaching of the gifted students required deep content and the students tended to have more demand for an in-depth understanding of the concept rather than memorizing (Taber, 2010). The example of this success can also be evidenced from their reflections via an online questionnaire that "I preferred the questions and examples being examined in-depth "or "this learning gave me a useful in-depth explanation that would guide my thinking." 
What response would gifted students give relative to the techniques and methods used to promote their creative thinking?

First of all, gifted students shared their comments about the effectiveness of techniques and methods used in the courses that they enjoyed the learning that helped to deepen their understanding and build their inspiration to think compared to the learning style that consumed a lot of times in memorizing theories and abstract ideas. For example, "very in-depth details", "The teaching made me know the rules underlying the proof", "I know more the reasons behind the theories", "incredibly in-depth "or "I appreciated the concept of calculus and could build up from this in the future ."

Moreover, they expressed their good pleasure with challenge-based learning, projectbased learning, and well-designed questions as these techniques and methods were tailored to augment their problem solving skills and promote their creative thinking in mathematical education. For instance, "it made me better understand and think", "it made me able to analyze the question", "I could use various approach to solve the question", "I do not like the acceleration style of learning because various possible approach and examples could not be introduced", or "I learned how to think and how to analyze."

Secondly, from the online questionnaire about attitudes towards learning, thirteen of them responded that the learning was challenging whereas some of them found it interesting with a few being frustrated. Seven of them replied that the content was appropriately depth and complicated while only a few of them faced some difficulties. The number of students reflected on the level of satisfaction on the lecture, question, and exercises, and project-based learning are provided in Table 1.

Table 1

Number (percentage) of students' reflection towardsthe level of satisfaction on the lecture, question, and exercises, and project-based learning

\begin{tabular}{lccccc}
\hline \multirow{2}{*}{ Item } & \multicolumn{5}{c}{ Level of satisfactory } \\
\cline { 2 - 6 } & lowest & low & medium & highly & most \\
& satisfactory & satisfactory & satisfactory & satisfactory & satisfactory \\
& 1 & 2 & 3 & 4 & 5 \\
\hline Lecture & 0 & 0 & 3 & 13 & 7 \\
& $(0.00 \%)$ & $(0.00 \%)$ & $(13.04 \%)$ & $(56.52 \%)$ & $(30.43 \%)$ \\
\hline $\begin{array}{l}\text { Questions } \\
\text { exercises }\end{array}$ & 0 & 0 & 0 & 12 & 12 \\
\hline $\begin{array}{l}\text { Project based } \\
\text { learning }\end{array}$ & $(0.00 \%)$ & $(0.00 \%)$ & $(0.00 \%)$ & $(52.17 \%)$ & $(47.83 \%)$ \\
\hline
\end{tabular}

In relation to the lecture, $56.52 \%$ of them found it highly satisfactory whereas up to $30.43 \%$ of them found it most satisfactory. For the question and exercise, $52.17 \%$ of them found it highly satisfactory and $47.83 \%$ of them found it most satisfactory. Regarding the project-based learning, $43.48 \%$ of them found it highly satisfactory while $21.74 \%$ of them found it most satisfactory.

The students' feedbacks and evaluation indicated that the techniques and methods used in this study could keep them motivated to learn in mathematics and to think creatively in the problem solving process. They also expressed their enjoyment of learning that offered a depth of knowledge and an adequate amount of challenge to elevate their thinking process. This confirmed the successful results from these techniques and methods . 


\section{Conclusion}

As gifted students are important social capital, who can contribute to countries' innovative development, they should receive learning that helps them to demonstrate their potential in particular of their creative thinking as well as to improve it. This study showed that teachers could invent several techniques and methods as external resources to promote their creative thinking both in and outside the classroom, including project-based learning, well-articulated questions, challenge-based learning, problem solving process, indepth learning style, and Facebook. This is in line with the findings by Crespo (2015) that teaching students to problem solve requires significant preparation from teachers to pose problems that are mindful, engaging, and socially relevant. Furthermore, this study also found that a combination of these techniques and methods gained support from a number of previous studies in this area as well as they corresponded well to the needs of the gifted students. In particular, the project "Water Wheel project" implemented in this study that required gifted students to work as a team in the real world situation is consistent with the previous studies that emphasized on collaboration with their peers in order to effective learning as well as on the transfer from theories into a suitable context for devising challenges. Additionally, this study also used the in-depth learning style and found in the same line with previous studies those students who were taught with in-depth knowledge, would explore and learn more. This was suggested in Tjoe (2015) that more mathematically experienced individuals will develop their perseverance in identifying an appealing solution beyond a correct solution as part of their process in learning and honoring mathematics as a subject. Similarly, the previous studies also supported that the teaching of gifted students required deep contents and they had more demand for an indepth understanding of the concept rather than memorizing. These techniques also aided them to think differently from the textbook-based framework and built up their insightful thought necessary for creative thinking development. Moreover, they should be moved away from learning on over-generalized explanations and theories into content-based learning. Finally, the learning environment was also an unavoidable factor because it could have a motivational effect on their learning and thus their abilities to think creatively.

\section{Acknowledgment}

The author would like to thanks referees for useful comments and suggestions which help to improve the manuscripts extensively.

\section{Bibliography}

Burney, V.(2008). Indiana mandate for high-ability identification and services signed by Governor Daniels: Record funding for high-ability students. , 31(1), 50. Gifted Child Today, 31(1), 50-51. Retrieved from https://search.proquest.com/openview/5b62c2ae9a40083b49e2fad55efc4bb4/1?cb l=46372\&pq-origsite $=$ gscholar

Clarke, L., \& Bana, J. (2001). Phantom classmates: A case study of talented mathematics students learning via telematics. In \& M. M. (Eds) In J. Bobis, B. Perry (Ed.), Proceedings of the Twenty-Fourth Annual Conference of the Mathematics Education Research Group of Australasia. Retrieved from https://ro.ecu.edu.au/ecuworks/4900/

Colangelo, N., \& Davis, G. A. (2002). Handbook of Gifted Education. Boston, MA: Pearson Education Press.

Diezmann, C. M., \& Watters, J. J. (2000). An enrichment philosophy and strategy for 
empowering young gifted children to become autonomous learners in science. Gifted and Talented International, 15(1), 16-18. https://doi.org/10.1080/15332276.2000.11672925

Diezmann, C. M., \& Watters, J. J. (2002). The Importance of Challenging Tasks for Mathematically Gifted Students. Gifted and Talented International, 17(2), 76-84. https://doi.org/10.1080/15332276.2002.11672991

Fraser-Seeto, K., Howard, S. J., \& Woodcock, S. (2013). Preparation for teaching gifted students: An updated investigation into university offerings in New South Wales. Australasian Journal of Gifted Education, 22(2), 45. Retrieved from https://ro.uow.edu.au/cgi/viewcontent.cgi?article=1604\&context=sspapers

Gagné, F. (1985). Giftedness and Talent: Reexamining a Reexamination of the Definitions. Gifted Child Quarterly, 29(3), 103-112. https://doi.org/10.1177/001698628502900302

Gagné, Françoys, \& Gagnier, N. (2004). The socio-affective and academic impact of early entrance to school. Roeper Review, 26(3), 128-138. https://doi.org/10.1080/02783190409554258

Geake, J. G., \& Gross, M. U. M. (2008). Teachers' Negative Affect Toward Academically Gifted Students: An Evolutionary Psychological Study. Gifted Child Quarterly, 52(3), 217231. https://doi.org/10.1177/0016986208319704

Khalil, M., \& Accariya, Z. (2016). Identifying "Good" Teachers for Gifted Students. Creative Education, 7, 407-418. https://doi.org/10.4236/ce.2016.73040

Koshy, V. (2001). Teaching Mathematics to Able Children.London: David Fulton Publishers. https://doi.org/10.4324/9780203065198

Landvogt, J. (2001). Affecting eternity: Teaching for talent development. Roeper Review, 23(4), 190-196. https://doi.org/10.1080/02783190109554097

Lassig, C. (2009). Teachers' Attitudes Towards the Gifted: The Importance of Professional Development and School Culture. Australasian Journal of Gifted Education, 18(2), 3242. Retrieved from search.informit.com.au/documentSummary ; $\mathrm{dn}=985113224788269 ;$ res=IELHSS\%3E ISSN: 1323-9686

Leikin, R. (2011). The education of mathematically gifted students: Some complexities and questions. The Mathematics Enthusiast, 8(1). Retrieved from scholarworks.umt.edu/tme/vol8/iss1/9

McCoach, D. B., \& Siegle, D. (2007). What Predicts Teachers' Attitudes Toward the Gifted? Gifted Child Quarterly, 51(3), 246-254. https://doi.org/10.1177/0016986207302719

Milgram, R. M. (1979). Perception of teacher behavior in gifted and nongifted children. Journal of Educational Psychology, 71(1), 125-128. https://doi.org/10.1037/0022$\underline{0663.71 .1 .125}$

Nevo, B., \& Rachmel, S. (2009). Education of Gifted Children: A General Roadmap and the Case of Israel. In Creativity in Mathematics and the Education of Gifted Students (R. Leikin,). Retrieved from https://edu.gov.il/owlHeb/GanaiYeladim/ Oclusiyotyechudiyot/Mechunanim/Documents/gifted1.pdf

Plunkett, D. M., \& Kronborg, D. L. (2011). Learning to Be a Teacher of the Gifted: The Importance of Examining Opinions and Challenging Misconceptions. Gifted and Talented International, 26(1-2), 31-46. https://doi.org/10.1080/15332276.2011.11673587

Plunkett, M. M. (2002). Impacting on Teacher Attitudes Toward Gifted Students.In W. Vialle, \& J. Geake (Eds.). In Victoria (Ed.), The Gifted Enigma: A Collection of Articles (pp. 240-259). Retrieved from research.monash.edu/en/publications/impacting-onteacher-attitudes-toward-gifted-students 
Scott, P. (1998). Teacher Talk and Meaning Making in Science Classrooms: a Vygotskian Analysis and Review. Studies in Science Education, 32(1), 45-80. https://doi.org/10.1080/03057269808560127

Shaywitz, S. E., Holahan, J. M., Freudenheim, D. A., Fletcher, J. M., Makuch, R. W., \& Shaywitz, B. A. (2001). Heterogeneity Within the Gifted: Higher IQ Boys Exhibit Behaviors Resembling Boys With Learning Disabilities. Gifted Child Quarterly, 45(1), 16-23. https://doi.org/10.1177/001698620104500103

Taber, K. . (2008). Towards a Curricular Model of the Nature of Science. Sci Ence and Education, 17(2-3), 179-218. https://doi.org/10.1007/s11191-006-9056-4

Taber, K. S. (2010). Challenging gifted learners: general principles for science educators; and exemplification in the context of teaching chemistry. Science Education International, 21(1), 5-30. Retrieved from //files.eric.ed.gov/fulltext/E]890658.pdf

Tjoe, H. (2015). Giftedness and Aesthetics: Perspectives of Expert Mathematicians and Mathematically Gifted Students. Gifted Child Quarterly, 59(3), 165-176. https://doi.org/10.1177/0016986215583872

Troxclair, D. A. (2013). Preservice teacher attitudes towards giftedness. Roeper Review, 35(1), 58-64. https://doi.org/10.1080/02783193.2013.740603

Vidergor, H., \& Reiter, prof. S. (2008). Satisfaction with School among Gifted Israeli Students Studying in Various Frameworks. Gifted and Talented International, 23(1), 29-50. https://doi.org/10.1080/15332276.2008.11673511

Ziv, Y., \& Sorongon, A. (2011). Social Information Processing in Preschool Children: Relations to Sociodemographic Risk and Problem Behavior. Journal of Experimental Child Psychology, 109(4), 412-429. https://doi.org/10.1016/j.jecp.2011.02.009 